University of Wollongong

Research Online

Faculty of Education - Papers (Archive)

Faculty of Arts, Social Sciences \& Humanities

$1-1-2010$

\title{
Beyond the 'digital natives' debate: towards a more nuanced understanding of students' technology experiences
}

Susan J. Bennett

University of Wollongong, sbennett@uow.edu.au

Karl A. Maton

kmaton@uow.edu.au

Follow this and additional works at: https://ro.uow.edu.au/edupapers

Part of the Education Commons

\section{Recommended Citation}

Bennett, Susan J. and Maton, Karl A.: Beyond the 'digital natives' debate: towards a more nuanced understanding of students' technology experiences 2010, 321-331.

https://ro.uow.edu.au/edupapers/1015

Research Online is the open access institutional repository for the University of Wollongong. For further information contact the UOW Library: research-pubs@uow.edu.au 
Beyond the 'digital natives' debate: Towards a more nuanced understanding of students’ technology experiences

Sue Bennett, Faculty of Education, University of Wollongong

Karl Maton, Department of Sociology and Social Policy, Faulty of Arts, University of Sydney 


\section{[0] Abstract}

The idea of 'the digital natives', a generation of tech-savvy young people immersed in digital technologies for which current education systems cannot cater, has gained widespread popularity on the basis of claims rather than evidence. Recent research has shown flaws in the argument that there is an identifiable generation, or even a single type of highly adept technology user. For educators, the diversity revealed by these studies provides valuable insights into students' experiences of technology inside and outside formal education. While this body of work provides a preliminary understanding, it also highlights subtleties and complexities that require further investigation. It suggests, for example, that we must go beyond simple dichotomies evident in the digital native debate to develop a more sophisticated understanding of our students' experiences of technology. Using a review of recent research findings as a starting point, this paper identifies some key issues for educational researchers, offers new ways of conceptualising key ideas using theoretical constructs from Castells, Bourdieu and Bernstein, and makes a case for how we need to develop the debate in order to advance our understanding. 


\section{[1] Introduction}

The idea that technology changes our lives profoundly is so ubiquitous in public discourse that it has become almost cliché. Both within and without the academy claims abound that technology is changing more rapidly than at any other time in human history. Often such claims convey a sense of urgency, pressing us to keep up with changes and raising concerns that some in our societies are being left behind. Cartoons humorously depict the gap between young people who have grown up with technology and an older generation for whom it appears to be a mystery or threat. Utopian visions of a brave new world unlocked by technological changes that promote greater equality and participation proliferate. What underpins all of these conceptions of modern life is the idea that advances in technology are creating societal changes which require new approaches and practices. Education, it is claimed, is a key arena for radical change.

Claims about change are common in social science. One can find a surfeit of 'singularities', one-off events viewed as revolutionary. Beniger (1986) lists seventyfive distinct names coined between 1950 and 1985 to describe such change. Fundamental social change, for example, has been variously described as creating a status society, service society, postindustrial society, postmodern society, knowledge society, and so on. Similarly, generations of students have been regularly described as fundamentally dissimilar - Babyboomers, Generation X, Generation Y, etc. - and are ascribed different characteristics. Indeed, moral panics over 'new' students are a recurrent phenomenon in education (Hickox \& Moore, 1995). During the late nineteenth century, for example, the expansion of formal state education was accompanied by concerns over the entry of middle-class and female students (Lowe, 1987). Similarly, policy debates in higher education during the early 1960s focused on the knowledge, interests and aptitudes of new, working-class students that expansion was expected to bring into universities (Maton, 2004). Current debates over the implications of technological change for education are similar in focusing another, supposedly new kind of learner. 
The argument is that radical change in education is needed because our traditional institutions do not meet the needs of a new generation of 'tech-savvy' learners. These young people are said to be different to all generations that have gone before because they think, behave and learn differently as a result of continuous, pervasive exposure to modern technology. Various labels have been applied to these young people, but the two most common are 'digital natives' (Prensky, 2001) and 'the Net Generation' (Tapscott, 1998). A key feature of the conception of young people as 'digital natives' is the apparently insurmountable gap between them and the less technologically literate older generations. The argument made is that "The single biggest problem facing education today is that our Digital Immigrant instructors, who speak an outdated language (that of the pre-digital age), are struggling to teach a population that speaks an entirely new language” (Prensky, 2001, p. 2).

This idea has excited a great deal of interest in the educational community and been widely taken up by commentators and researchers (eg. Barnes, Marateo, \& Pixy Ferris, 2007; Downes, 2005; Toledo, 2007). Despite recent empirical evidence undermining claims about profound age-related differences in technology use and practices (eg., see other papers in this special issue), and moves by the original authors to distance themselves from their original claims (eg. Prensky, 2009), the idea put forward of a fundamental gap between the technologically skilled and unskilled persists. The slightly modified version of the argument posits that there exists a portion of the population who are highly adept technology users and that these people are fundamentally different in their behaviours and preferences to those who are not because of their use of technology (Dede, 2005; Oblinger, 2005). So while this assertion no longer excludes older people with sufficient exposure to digital technologies, there is still an assumption that younger people are naturally more tech savvy. Thus, while it may be argued that some have moved on from simple conceptions of an age-based divide, an undercurrent of technological determinism persists in debates.

This paper sets aside the issue of generational differences, and focuses on claims made about young people and their technology experiences, because it is these claims that are driving the debate about educational change. There are varied views about young people's use of technology, ranging from expressions of grave concern about 
lack of socialisation and poor interaction skills, Internet addiction and cyberbullying (eg. Cross et al, 2009), to idealisations of a new generation of highly motivated, highly technologised learners (eg., Lorenzo et al, 2007). In short, there is a significant lack of consensus over what effects digital technology is actually having on young people. Here we adopt an agnostic position, asking instead what the research evidence suggests and offering suggestions for how researchers might conceptualise the problem in such a way as to advance understanding in this area. First, we examine what current research suggests about young people’s use of technology.

\section{[2] Research on access to technology}

A longstanding focus of research has been the extent of young people's access to technology, because it is an obvious precursor to technology use. For example, in the early days of computers in schools there was a significant focus on the level of computer provision and technology infrastructure in schools (eg., CEO Forum, 1999). Additionally, access to technology is relatively easy to measure and has therefore been included in most surveys which aim to quantify aspects of young people's technology use.

Surveys of university students, for example, have found that access to some technologies is almost universal. Very high proportions of students have access to their own mobile phone and sole access to either a laptop or desktop computer (Oliver \& Goerke, 2007; Kennedy et al, 2009; Margaryan \& Littlejohn, 2008). The same studies show that access to other technologies is more mixed or, in the case of PDAs and handheld computers, quite limited. The key reasons for the lesser popularity of these devices, as explained by students in focus group interviews, have been their high cost and lack of distinct advantage over technologies that students already use (Salaway \& Caruso, 2008). This is understandable given that young people are sensitive to cost and often opt for less expensive alternatives, such as sending text messages rather than making telephone calls. Some longitudinal surveys have been useful in detecting changes in access patterns (eg., the ongoing ECAR study of undergraduate students and information technology). These show that some technologies become more popular, while others decline. Obvious recent examples 
are the increase in laptop computer ownership and broadband access amongst students, with a decline in dial-up internet use (Salaway \& Caruso, 2008). Such changes, enabled by lower costs to consumers, mirror changes in the general population in many developed countries.

While this information provides useful data about the array of technological devices available to young people, qualitative research highlights some of the difficulties with interpreting measures of access to technology. Studies of school-aged children in particular have highlighted differences in the ways home access to technology is determined according to the location of the computer, rules about access and the value placed on technology as an educational or recreational device (Downes, 1998; Kerawalla \& Crook, 2001). In some households, one or more parents may be observed using the computer as a work tool, modelling particular types of use to children in the household or involving children in a home-based business (Thrupp, 2008). In other households technology use may be directed toward particular activities or restricted in the belief that overuse may be harmful or that there is a risk of the computer being damaged (eg., Hargittai \& Hinnant, 2008). Differences in access in different locations can further complicate the issue. For example, a study of primary school children in Australia showed that despite very low access to technology outside of school (as low as 5\% in some classes), students at one disadvantaged school had high levels of access to computers at school for both academic and non-academic purposes (Campbell, 2006). Other studies, however, have shown that school use does not always mitigate low access at home (Facer \& Furlong, 2001). These studies demonstrate that "access is a far more complex issue than mere provision of facilities” (Furlong et al., 2000, p. 94) because the availability of a computer does not necessarily mean genuine access.

It is difficult to compare the findings about access between school aged children and university students on the basis of the data currently available and differences in the ways the research has been constructed. Studies of school-aged children have typically been more careful in distinguishing between access in different contexts (namely home and school) and have explored what that access means in practice. Less is known about technology access in the different contexts in which young adults engage (eg. Committee of Inquiry into the Changing Learner Experience, 2009). It 
may be that some of the complexities of access are resolved as young people grow up, become more independent and have more freedom in their access to technology as they reach university. It may also be that university students tend to come from higher socio-economic backgrounds and therefore experience fewer difficulties in accessing technologies. The tentative nature of these suggestions reflects current gaps in our understanding.

What these studies suggest is that young people grow up with different histories of access to technology and therefore different opportunities. This leads to the conclusion that measures of access tell only part of the story and that it may be more important to understand the nature of the technology-based activities in which young people engage. Some progress has been made towards addressing these questions by studies that seek to investigate the extent to different types of technology-based activities.

\section{[3] Research on technology-based activities}

In asking questions concentrated more on activities than access, researchers have tried to move the focus away from particular technologies and more towards the types of activities those technologies support, such as communication, information access, and content creation, often including both academic and everyday activities (eg. Kennedy et al, 2009; plus other papers in this special issue). Key challenges in the development of surveys include determining how fine-grained items should be (for example, deciding whether it is important to distinguish between communication by email and instant messaging) and ensuring that the language used results in a valid item when technical terms are not commonly used in ordinary parlance (for example, explaining terms like 'social networking' or 'microblogging' using the names of common tools). Large scale surveys investigating the frequency of technology-based activities are often complemented by interviews which seek to discover the reasons underlying patterns in the data (eg. Kennedy et al. 2009; Salaway \& Caruso, 2008).

A common finding amongst the various studies is that some activities are undertaken frequently by a majority of respondents. This is particularly so for accessing 
information and communicating via the Internet and mobile technologies (eg. Kennedy et al. 2009; Salaway \& Caruso, 2008). Other technology-based activities are undertaken by fewer respondents and/or less frequently. For example, content creation activities as measured by items such as creating text, graphics, audio or video are consistently lower than might be anticipated given many claims about what young people are doing with technology. In fact, with the exception of social networking, most activities associated with Web 2.0 are engaged in by a minority of respondents on key large scale surveys (eg. Kennedy et al., 2009; Salaway \& Caruso, 2008; Jones et al, in press). Interview data from one study revealed that many students were unsure what some Web 2.0 tools, such as blogs and wikis, were (Kennedy et al., 2009). Such findings run counter to claims made about the creativity of this new generation, such as:

Constantly connected to information and each other, students don't just consume information. They create - and re-create - it. With a do-ityourself, open source approach to material, students often take existing material, add their own touches, and republish it. Bypassing traditional authority channels, self-publishing - in print, image, video, or audio - is common.” (Lorenzo et al, 2007; p. 2)

Surveys of young adults also suggest that game playing, another activity commonly associated with young people's technology use and preferences (Prensky, 2001), is also lower than might be expected (Kennedy et al., 2009). Such findings appear at odds with some studies indicating high levels of game playing amongst children and teenagers (eg. Downes, 2002; Kent \& Facer, 2004), but may suggest that time and motivation for computer or console based game play may decline at later life stages when young people have both more freedom from home and more responsibilities involving work and education. Some studies of children and teenagers suggest that specialisation in particular types of technology-based activities may develop at an early age. For example, Thrupp (2008) identified 'gamers', a group highly engaged in computer game playing, as a particular sub-group in her study of primary school children's technology-based activities. These children could be differentiated from others in the study who played games some of the time, but demonstrated different specialisations or interests both on and off the computer. Green and Hannon (2007) 
suggested different user types with their own particular expertise: 'digital pioneers', ‘creative producers’, ‘everyday communicators’ and ‘information gatherers’.

Importantly, it is these studies of technology-based activities, rather than those measuring access, that have begun to highlight significant variations across age, gender and socio-economic status (eg., Livingstone \& Helsper, 2007; Selwyn, 2008). These appear more pronounced in studies of school-aged children than in university students, which might be explained by schools encompassing a broader population than universities. Put simply, university student populations are not representative of the broader population; for example, they are skewed towards higher socio-economic sections of the community (Bradley et al., 2008).

In essence what these research findings suggest is that while there are some very common technology-based activities engaged in frequently by a majority of respondents, beyond this subset frequency of use and extent of use within these populations of young people is highly varied. There are some who engage in a wide range of technology-based activities, including content creation and self-publishing, at high frequencies, while there are significant numbers amongst the same sample who never participate in those activities. In addition there are a spread of moderate users. Qualitative research provides some insights into the choices young people make about technology, suggesting that technology is used for particular, highly contextualised purposes and chosen for its value, its suitability for the purpose, and the nature of the interactions offered. A further suggestion from the findings is that the activities engaged in may be significantly influenced by both the life stage of the young person and the interests s/he wishes to pursue.

It is clear from this recent research that there is significant variation in the ways in which young people use technology, suggesting that rather than being a homogenous generation, there is a diversity of interests, motivations and needs. So while some young people might be regarded as 'digital natives', these are by no means characteristics shared by all young people simply because of their exposure to digital technologies. Although progress has been made in investigating this phenomenon, there are significant gaps in our understanding. More research is needed into what young people choose to do with technology and why, what it is they value and what 
they do not, according to the contexts in which they engage. Having reviewed some of the recent research evidence about young people's technology use, we now turn our attention back to education and consider the key issues for educational researchers.

\section{[4] Key issues for educational researchers}

The lack of evidence for the existence of an entire generation of digital natives seriously undermines arguments made for radical change to education because of a disjuncture between the needs of young people and their educational institutions. This is not to say education should not change at all, merely that the basis of the argument as it is currently made is fundamentally flawed. This does not mean that we cannot learn more about our students and consider what use we might put this new knowledge to. Indeed, a valuable outcome of the current research agenda has been to demonstrate just how diverse learners of all ages are in their technology experiences. Coming to understand what this means raises a series of inter-related issues about the nature of education and its role in young people's lives.

First, we can consider what these findings mean to the goal of integrating popular new technologies to support learning. The advent of new technology always raises questions and claims about how it can be used effectively in education. In turn, these raise questions of the extent to which skills, interests and values developed in everyday technology-based activities can be transferred to academic contexts. Current research suggests that this is likely to be highly variable and that students may not be as skilled with technology as often assumed, particularly with advanced activities (Kennedy et al, 2009; Salaway \& Caruso, 2007; Singh, Mallan \& Giardina, 2008). The conclusion is that the familiar issues of equity and student training still need to be considered.

A more subtle point is that everyday technology-based activities may not prepare students well for academic practices. For example, general information-seeking strategies may have limited application to tasks requiring synthesis and critical evaluation (Jenkins, 2006). For example, writing a blog while travelling abroad may not equip students with the skills they need to use the same technology to develop a reflective journal as part of their studies - the nature of the tasks and the forms taken 
by the knowledge being constructed are different. Additionally, norms and values may not transfer from everyday situations to academic tasks. For example, while comments from others may be valued within communities of interest (for example, a forum devoted to mountain bike riding), information from peers may be ascribed lesser value in an academic context in which students do not trust their classmates to be right (see examples from Web 2.0 implementations in Kennedy et al, 2009; Clark et al, 2008).

Of course, many of these issues would become irrelevant if education became more like everyday life; i.e. if formal learning became more like informal learning. Indeed, this is often prescribed as the solution (Prensky, 2001; Tapscott, 1998). Much of this discussion de-privileges education, teachers and knowledge, while valorising the attributes of the tech-savvy student. This student is held to feel disengaged and disenfranchised while education is cast as unchanged, unchanging and unchangeable (Bayne \& Ross, 2007). Such characterisations serve us all poorly. Not only do they fail to acknowledge the ways in which formal education does change, but they devalue it to such an extent that it is difficult to comprehend what it could offer. It is to discount wholly the notion that formal education can and does provide an important complement to informal learning (Facer et al, 2001; Jenkins, 2006).

A more promising approach is to consider formal educational contexts and everyday contexts as being different, comprising of different activities with different purposes and outcomes, without necessarily privileging one over the other. We also need to move beyond a simple dichotomy between 'everyday' and 'education'. In reality, young people engage in a wide range of different contexts, many of which entail learning in more or less formalised ways, and even within educational institutions there exists an array of learning settings. The most useful stance therefore is to strive to understand what knowledge and assumptions students bring to academic contexts from other aspects of their lives, and what that means to teaching and learning. To do so we need more sophisticated ways of conceptualising research that will also enable us to move beyond description and towards explanation. The next section will discuss concepts from the sociology of education and knowledge which offer possible means for accomplishing this move forward. 


\section{[5] Conceptualising the issues}

Castells's (2001) notion of 'networked individualism' provides a useful starting point for how we might build a conceptual framework for further investigating young people’s technology experiences. Castells proposes that the Internet provides material support for a "new pattern of sociability based on individualism" (Castells, 2001, p.130) which connects people not only through traditional family and local community networks, but also through geographically dispersed social networks connected by computer communications. In this vision of the modern world these new societal structures enable people to engage in "multiple, partial communities as they deal with shifting, amorphous networks of kin, neighbours, friends, workmates and organisational ties” (Wellman, 2002, p. 2). In this conceptualisation, each person navigates his or her own personal network, involvement in networks varies from person to person, people sometimes take on specialised roles in different networks, and loose networks of interest with weak ties evolve and devolve. As such our focus becomes the networked individual and his or her experience of the world via these networks. In terms of young people's technology use, the focus is placed on the individual and on how they experience the different contexts in their networks through the technologies they use. At the very least, such a conception alerts us to the variegated and shifting nature of the many contexts in which young people engage during the course of their daily lives. The next step is thus to develop a conceptualising these different contexts in ways that move us beyond such reductive dichotomies as 'everyday' and 'educational'.

Bourdieu's interconnected concepts of 'field', 'capital' and 'habitus' provides one means of analysing the varied contexts in which people operate in their networks (Bourdieu \& Wacquant 1992). According to Bourdieu (1990), actors occupy a variety of social fields of practice, each with its own unwritten 'rules of the game' or ways of working and acting that structure these different contexts. For Bourdieu practices are shaped by: actors' 'habituses' (or dispositions structured by experiences); their 'capital' (the status and resources they possess and thus their position in the hierarchies of any particular context); and the state of play in struggles for status in the 'fields' or contexts they occupy (Lingard \& Christie, 2003; Maton, 2005). 'Field' conceptualises social contexts in terms of their degree of relative autonomy from 
other contexts (e.g. whether the dominant ways of acting, values and interests are specific to the context or drawn from other fields), and relations between actors in terms of status hierarchies (e.g. whether actors are considered expert authorities or marginal participants). 'Capital' conceptualises the basis of these positions in terms of what is at stake in struggles for status and resources; i.e. what underpins authority, what is valued, what actors gain from their participation, etc. 'Habitus' conceptualises the embodied dispositions that actors carry across the varied contexts of their daily lives, drawing attention to such issues as social and educational backgrounds, how actors come to be involved in particular practices, and how they learn their practices. Drawing on this approach places the technology practices of young adults at the centre of the various and varied, relatively autonomous social worlds in which they are situated. Using Bourdieu's 'field' theory would thus reveal the different structures and practices associated with different educational contexts and different everyday contexts, enabling them to be viewed both less homogeneously and less dichotomously. This enables a more nuanced understanding than previous conceptualisations which have drawn a sharp distinction between the everyday world and education, without acknowledging that there are many and varied contexts in which young people engage with technology ${ }^{1}$.

Using only Bourdieu's approach, however, would focus more on the social dimensions of practices than the forms of knowledge produced. As recent critiques argue, Bourdieu's concepts are useful for analysing the nature of contexts, but not the nature of the knowledge and practices actors engage with in those contexts (Maton, 2003, 2005; Moore, 2007). The work of Bernstein offers a theory of the forms taken by knowledge. For example, Bernstein's concepts conceptualise important differences between knowledge gained through informal everyday contexts and knowledge developed in formal educational contexts. 'Horizontal discourse' or everyday knowledge is more "contextually specific and 'context dependent', embedded in ongoing practices... and directed towards specific immediate goals, highly relevant to the acquirer in the context of his/her life” (Bernstein, 1999, p. 161). Usually acquired in social relations with a strong affective loading, such as the family and peer group, the knowledge gained takes a segmented form, its meaning typically related to

\footnotetext{
${ }^{1}$ See North, Synder and Bulfin (2008) for an example of how Bourdieu's concepts can be applied to young people's technology use.
} 
specific contexts. As a result, what is learned in one context may bear little relation to what is learned in another. As Bernstein puts it, "Learning how to tie up one's shoes bears no relation to how to use the lavatory correctly" (1999, p. 160).

In contrast, the meaning of 'vertical discourse' or educational knowledge is less related to specific contexts but rather related to other knowledge and 'takes the form of a coherent, explicit, and systematically principled structure' (1999, p.159). The meaning of educational knowledge is given by its relations with other meanings rather than its social context. Moreover, these meanings are related in particular ways for the explicit purpose of formal education. For example, as Moss (2001) explains, educational knowledge is:

always sequentially ordered. What is known now gains its significance from what comes next, as well as what has gone before. In this sense knowledge enacted at a particular moment in formal settings is never selfcontained, but always points both onward and back, creating strong development trajectories.

In short, a defining characteristic of knowledge gained in a formal educational context is that it is pedagogised knowledge. That is, it is knowledge that has been selected, rearranged into a particular sequence within a curriculum, and recontextualised within specific contexts of teaching and learning (Singh, 2002). Such a conception recognises the important role of the teacher, such as relating current learning activities to what students have already learned and what they will learn in the future.

Educational knowledge is thus not simply the same as everyday knowledge but located in an educational context: it has a different form ${ }^{2}$. Moreover, not all educational knowledge has the same form. Bernstein goes further to conceptualise the different forms taken by knowledge in terms of different 'knowledge structures'. This highlights, as a growing range of studies are showing, that the forms taken by knowledges in different disciplines are different, as are their structures of curriculum, pedagogy and assessment, in ways that cannot simply dismissed or wished away (Christie \& Martin 2007; Maton \& Moore 2010). Where Bourdieu’s approach enables

\footnotetext{
2 This distinction between everyday and educational knowledge is not based on a dichotomy between inside and outside formal education. Bernstein's notion focuses not on the location of the context but on the structure of the knowledge and practices themselves. So it is possible for a context outside school to exhibit a 'vertical' structure.
} 
differences between contexts to be systematically theorised in a less simplistic way, Bernstein's concepts thereby enable differences between the knowledges and practices of these contexts to be understood in a less dichotomous and homogenising manner.

It is insufficient to simply state that the lives of young people involve multiple, complex and overlapping social universes; to understand the role technology plays one needs to be able to theorise those universes and the varied forms of knowledge and practices they involve. Using these concepts as a theoretical lens through which to conceptualise the social practices and the forms of knowledge in the different contexts in which a person engages provides a further basis for conducting research into young people's technology experiences. They provide an entrée into the complex worlds people inhabit and suggest a means by which we can build a more sophisticated understanding of current phenomena. They may provide insights into why technologies are useful in representing knowledge, learning and interacting differently in different contexts, everyday and academic, and across disciplines. It is these insights that may provide a better basis for predicting which 'everyday' technology-supported activities have most relevance for which forms of formal education, when, where, how and for which students.

We are not arguing that these are the only possible research approaches or questions, merely that they are suggested by the trajectory of the current findings of research. A wide range of studies from other perspectives may be valid, and there are likely to continue to be multiple ways of conceptualising and investigating this research area. However, as we shall now argue, this research will only be able to advance knowledge if the nature of the debate over 'digital natives' itself advances.

\section{[6] Advancing the debate over 'digital natives'}

In addition to the need for more research evidence as an empirical base for discussions about young people's technology experiences, the tenor of the debate needs to change. Elsewhere we have argued that much of the discussion about digital natives has taken the form of an 'academic moral panic', in which dramatic language 
proclaiming profound change and a series of strongly bounded divides close down genuine debate (Bennett et al, 2008). Two other concepts are useful in characterising why the current discussion has been resistant to the intellectual rigour it requires and deserves: 'historical amnesia' and the 'certainly-complacency spiral'.

A key feature of the debate so far is 'historical amnesia' (Maton, forthcoming). Declarations of fundamental change obscure if not explicitly deny past precedents for contemporary change. Such arguments proclaim a rupture or radical break with the past, rendering the field unable to address the very claim upon which the phenomenon is based, namely social and intellectual change (eg. Prensky, 2001; Tapscott, 1998). Such sentiments betray amnesia about the history of education. They are the same as claims made, for example, in the late 1950s and early 1960s about a generation of students immersed in new forms of commercial culture, such as television and popular music. Schools and the everyday lives of young people were held to be radically different and "the children have to live with a foot in both these worlds" (National Union of Teachers, 1960, p.26). Such precedents are, however, erased in the digital natives debate, accentuating the apparent 'newness' of the current situation. ${ }^{3}$ Erasing the past in this way renders social and intellectual change an 'article of faith' rather than an 'object of inquiry' (Moore \& Maton, 2001). The past becomes a 'foreign country' and the young and old are considered to inhabit different worlds. Given the research evidence to the contrary and the illogic of such a position, it is futile to continue with these kinds of arguments.

This thinking also prevents us from discriminating between genuinely new phenomena and those which are extensions of existing interests and well-recognised behaviours (Golding 2000). Something that has changed is the extent to which some activities which were previously ephemeral are now made visible on a forum or social networking site (see Dunkels (2006) idea of 'surfacing'). Selwyn's (2007) study illustrates this phenomenon well by demonstrating how previously unobserved behaviours, such as students complaining about teaching staff or asking each other about assignments, are made manifest when recorded on Facebook. Despite the use of

\footnotetext{
${ }^{3}$ There is, however, a new twist on the familiar idea of the 'generation gap'. In earlier debates young people's engagement with popular culture was considered intrinsically damaging. By contrast, in the digital native argument young people's technology use is considered intrinsically good and it is the older generation that must 'catch up'.
} 
a new medium, these are clearly not new phenomena, although their new visibility might have implications for teachers and students. A more serious example is the way that bullying has found new vehicles through the Internet and mobile phones. Many bullying behaviours are variants on familiar interactions, so casting them as 'entirely new’ may be unnecessarily alarmist because current anti-bulling strategies may still be effective or capable of adaptation. Equally though, understanding the implications of new forms made possible by technology are important for extending current strategies to appropriately address this evolving problem.

Another feature of the debate is what can be termed a 'certainty-complacency spiral' that enables the uncritical reproduction of the terms 'digital native' or 'Net generation' in ways that both give them a credence they do not deserve and amplifies their significance. The more certain authors are that digital natives exist, the less likely they seem to be to question claims made about them by other authors. For example, publications comprising unevidenced claims have often been routinely cited as if they contained researched evidence. This complacent, uncritical acceptance of the veracity of such claims in turn encourages further certainty, as the number of publications adopting the term grows. Belief replaces considered debate, and echoing commonsense perceptions of fundamental change and citations of similar claims made by other authors substitute for research evidence. Each proclamation of the existence and needs of 'digital natives' thereby iteratively amplifies and reinforces the sense of certainty and encourages intellectual complacency. Rather than representing bold conjectures to be tested, claims become unquestioningly repeated as if established facts, restricting the possibility of open, rational debate. Intellectual complacency over the veracity of claims (whether digital natives exist, whether they take the form ascribed, and whether education needs changing in the ways called for) is masked by the urgency and stridency with which calls for change are made. Indeed, those who pause for thought or raise questions can be described as complacent in the face of an impending crisis. Thus, intellectual complacency and sensationalist declarations of an educational emergency - an academic moral panic - may go hand in hand.

Couching this case in terms of fundamental change also privileges those making the claims. To question the break is to be assigned to the other side, those people who 
cannot or will not see the break, those people who 'don't get it' (Maton \& Moore, 2000). We should emphasise we are in no way suggesting a conscious suppression of scepticism, nor that everyone involved in the debate exemplifies this position. Rather we are arguing that the way the debate has been constructed by some digital native proponents is working against the advancement of knowledge in this area. If we really want to understand young people's technology experiences and what should happen to education because of them, we need to move the debate on to be less self-interested and more dispassionate. 


\section{[7] Conclusion}

Given the growing body of evidence that simultaneously refutes the simple notion of the 'digital native' and highlights the complexities of young people's technology experiences, it is timely to reflect on the emerging research agenda. Clearly it will continue to be important to measure access and activity through large scale surveys. These provide general information about in patterns of engagement, trends over time, and the broad characteristics of sub-groups as technology use changes and new technologies emerge. By the same token, qualitative methods will continue to be critical to acquiring in-depth insights into the basis for differences in access and activity and what they mean in the lives of individuals. There is now an excellent foundation for further research, but we suggest that this research would benefit from a more theoretically informed basis. We suggested some ways of conceptualising these research issues drawing on theories from the sociology of education and knowledge, but this does not preclude other perspectives. We also argued that to move the debate forward we must change its nature and engage with the important researchable issues, rather than taking up opposing positions. It is, we have argued, time to move beyond the 'digital natives' debate as it currently stands and towards a more sophisticated, rational debate that can enable us to provide the education that young people deserve. 


\section{[8] References}

Barnes, K., Marateo, R., Pixy Ferris, S. (2007). Teaching and learning with the Net Generation. Innovate, 3(4). Retrieved September 5, 2009, from http://innovateonline.info/index.php?view=article\&id=382\&action=article

Bayne, S. \& Ross, J. (2007). The 'digital native' and 'digital immigrant': A dangerous opposition. Paper presented at the Annual Conference of the Society for Research into Higher Education, Liverpool, UK, 9-11 December, 2007. Retrieved August 5, 2009, from: http://www.malts.ed.ac.uk/staff/sian/natives_final.pdf

Beniger, J. (1986). The Control Revolution: Technological and economic origins of the information society. Cambridge, MA, Harvard University Press.

Bennett, S., Maton, K., \& Kervin, L. (2008). The ‘digital natives’ debate: A critical review of the evidence. British Journal of Educational Technology, 39(5), 775786.

Bernstein, B. (1999). Vertical and horizontal discourse: An essay. British Journal of Sociology of Education, 20(2), 157-173.

Bourdieu, P. (1990). The Logic of Practice. Cambridge: Polity.

Bourdieu, P. \&. Wacquant, L. J. D. (1992). An Invitation To Reflexive Sociology. Cambridge: Polity Press.

Bradley, D., Noonan, P., Nugent, H. \& Scales, B. (2008). Review of Australian higher education: Final report. Canberra: Commonwealth of Australia.

Campbell, C. (2006). The role of the internet in the primary school classroom. Unpublished doctoral dissertation. University of Wollongong, Australia.

Castells M. (2001). The Internet Galaxy. New York: Oxford University Express.

CEO Forum. (1999). The CEO Forum school technology and readiness report.

Retrieved October 19, 2009, from

http://www.ceoforum.org/downloads/99report.pdf

Christie, F. \& Martin, J. (Eds.) (2007). Language, Knowledge and Pedagogy: Functional linguistic and sociological perspectives. London: Continuum.

Clark, W., Logan, K., Luckin, R., Mee, A., \& Oliver, M. (2008). Beyond Web 2.0: mapping the technology landscapes of young learners. Journal of Computer Assisted Learning, 25, 56-69. 
Committee of Inquiry into the Changing Learner Experience. (2009). Higher Education in a Web 2.0 World. Report of an independent Committee of Inquiry into the impact on higher education of students' widespread use of Web 2.0 technologies. Retrieved January 6, 2010, from http://www.jisc.ac.uk/media/documents/publications/heweb20rptv1.pdf

Cross, D., Shaw, T., Hearn, L., Epstein, M., Monks, H., Lester, L., \& Thomas, L. (2009). Australian Covert Bullying Prevalence Study. Child Health Promotion Research Centre, Edith Cowan University, Perth. Retrieved October 17, 2009, from

http://www.deewr.gov.au/Schooling/NationalSafeSchools/Pages/research.aspx

Dede, C. (2005). Planning for neomillennial learning styles: Implications for investments in faculty and technology. In D. Oblinger \& J. Oblinger (Eds.), Educating the Net Generation (pp. 15.1-15.22). Boulder, CO: EDUCAUSE. Retrieved March 31, 2006, from http://www.educause.edu/educatingthenetgen

Downes, S. (2007). Places to go: Google’s search results for the "Net Generation”. Innovate, 3(4). Retrieved June 27, 2007, from http://www.innovateonline.info/index.php?view=article\&id=455

Downes, T. (1998). Using the computer at home. In M. Monteith (Ed.), IT for Learning Enhancement. Oxford: Intellect Books.

Downes, T. (2002). Blending play, practice and performance: children's use of computer at home. Journal of Educational Enquiry, 3(2), 21-34.

Dunkels, E. (2006). The Digital Native as a student: Implications for Teacher Education. Tidskrift för lärarutbildning och forskning (Journal of Research in Teacher Education), 1, 43-56.

Facer, K. \& Furlong, R. (2001), Beyond the myth of the 'cyberkid': Young people at the margins of the information revolution. Journal of Youth Studies, 4(4), 451-69.

Furlong, J., Furlong, K., Facer, K., \& Sutherland. S. (2000). The national grid for learning: a curriculum without walls? Cambridge Journal of Education. 30(1), 91110.

Golding, P. (2000). Forthcoming features: Information and communication technologies and the sociology of the future. Sociology 34(1), 165-184.

Green, H. \& Hannon, C. (2007). Young people are spending their time in a space which adults find difficult to supervise or understand. Report. London: Demos. 
Retrieved October 19, 2009, from

http://www.demos.co.uk/files/Their\%20space\%20-\%20web.pdf

Hargittai, E. \& Hinnant, A. (2008). Digital Inequality. Differences in young adults’ use of the internet. Communication Research, 35(5), 602-21.

Hickox, M., \& Moore, R. (1995). Liberal-humanist education: The vocationalist challenge. Curriculum Studies, 3(1), 45-59.

Jenkins, H. (2004). The myths of growing up online. Technology Review. Retrieved October 19, 2009, from http://www.technologyreview.com/Biotech/13773/

Jones, C., Ramanaua, R., Cross, S., \& Healing, G. (in press). Net generation or Digital Natives: Is there a distinct new generation entering university? Computers and Education. (Accepted 15 September 2009)

Kennedy, G., Dalgarno, B., Bennett, S., Gray, K., Waycott, J., Judd, T., Bishop, A., Maton, K., Krause, K., \& Chang, R. Educating the Net Generation - A Handbook of Findings for Practice and Policy. Australian Learning and Teaching Council. Retrieved October 19, 2009, from http://www.altc.edu.au/system/files/resources/CG625_Melbourne_Kennedy_Handbook_July09.pdf

Kent, N. \& Facer, K. (2004). Different worlds? A comparison of young people’s home and school ICT use. Journal of Computer-Assisted Learning, 20(6), 440-55.

Kerawalla, L. \& Crook, C. (2002),Children's computer use at home and at school: context and continuity. British Educational Research Journal, 28(6), 751-71.

Livingstone, S. \& Helsper, E. (2007). Gradations in digital inclusion: Children, young people, and the digital divide. New Media \& Society, 9(4), 671-696.

Lorenzo, G., Oblinger, D. \& Dziuban, C. (2007) How choice, co-creation, and culture are changing what it means to be net savvy. Educause Quarterly 30(1).

Lingard, B. \& Christie, P. (2003). Leading theory: Bourdieu and the field of educational leadership. International Journal of Leadership in Education, 6(4), 317-333.

Lowe, R. A. (1987). Structural Change in English Higher Education, 1870-1920. The Rise of the Modern Educational System. Cambridge: Cambridge University Press.

Margaryan, A., \& Littlejohn, A. (2009). Are digital natives a myth or reality?: Students' use of technologies for learning. Retrieved January 6, 2010, from http://www.academy.gcal.ac.uk/anoush/documents/DigitalNativesMythOrRealityMargaryanAndLittlejohn-draft-111208.pdf 
Maton, K. (2003). Reflexivity, relationism and research: Pierre Bourdieu and the epistemic conditions of social scientific knowledge. Space \& Culture, 6(1), 52-65.

Maton, K. (2004). The wrong kind of knower: Education, expansion and the epistemic device. In Muller, J., Davies, B., \& Morais, A. (Eds.) Reading Bernstein, Researching Bernstein (pp. 218-231). London, Routledge.

Maton, K. (2005). A question of autonomy: Bourdieu's field approach and policy in higher education Journal of Education Policy, 20(6), 687-704.

Maton, K. (forthcoming) Knowledge and Knowers: Towards a realist sociology of education. London, Routledge.

Maton, K. \& Moore, R. (2000). Historical amnesia: Victims of fashion and outbreaks of 'breaks' in the disciplinary map. Paper presented at British Sociological Association Annual Conference, University of York, April. Retrieved June 27, 2007, from http://www.autodidactproject.org/other/matonha.html.

Maton, K. \& Moore, R. (2010) (Eds.) Social Realism, Knowledge and the Sociology of Education: Coalitions of the mind. London, Continuum.

Moore, R. (2007) Sociology of Knowledge and Education. London, Continuum.

Moore, R. \& Maton, K. (2001) Founding the sociology of knowledge: Basil Bernstein, intellectual fields and the epistemic device. In A. Morais, I. Neves, B. Davies \& H. Daniels (Eds.), Towards a Sociology of Pedagogy: The contribution of Basil Bernstein to research (pp. 153-182). New York:Peter Lang.

Moss, G. (2001). On literacy and the social organisation of knowledge inside and outside school, Language and Education, 15(2 \& 3), 146-161.

National Union of Teachers. (1960). Popular Culture and Personal Responsibility: Verbatim report. London: NUT.

North, S., Snyder, I. \& Bulfin, S. (2008). DIGITAL TASTES: Social class and young people’s technology use. Information, Communication \& Society, 11(7), 895-911.

Oblinger, D. \& Oblinger, J. (2005). Is it Age or IT: First steps towards understanding the net generation. In D. Oblinger \& J. Oblinger (Eds.), Educating the Net Generation (pp. 2.1-2.20). Boulder, CO: EDUCAUSE. Retrieved March 31, 2006, from http://www.educause.edu/educatingthenetgen

Oliver, B. and Goerke, V. (2007). Australian undergraduates' use and ownership of emerging technologies: Implications and opportunities for creating engaging learning experiences for the Net Generation. Australasian Journal of Educational Technology, 23(2), 171-186. Retrieved June 27, 2007 from, 
http://www.ascilite.org.au/ajet/ajet23/oliver.html

Prenksy, M. (2001). Digital Natives, Digital Immigrants. On the Horizon, 9(5), 1-6.

Prensky, M. (2009). H. sapiens digital: From digital immigrants and digital natives to digital wisdom. Innovate, 5(3). Retrieved February 4, 2009, from http://innovateonline.info/index.php?view=article\&id=705

Salaway, G. \& Caruso, J. (2007). The ECAR Study of Undergraduate Students and Technology. Boulder, Co; EDUCAUSE.

Selwyn, N. (2007). ‘Screw Blackboard... do it on Facebook!': an investigation of students' educational use of Facebook. Paper presented at the Poke 1.0 - Facebook Social Research Symposium, University of London, 15 November 2007. Retrieved January 6, 2010, from http://www.scribd.com/doc/513958/Facebook-seminarpaper-Selwyn

Selwyn, N. (2008) An investigation of differences in undergraduates' academic use of the internet. Active Learning in Higher Education, 9(11), 11-22.

Singh, P. (2002). Pedagogising knowledge: Bernstein's theory of the pedagogic device. British Journal of Sociology of Education, 23(4), 571-582.

Singh, P., Mallan, K. \& Giardina, N. (2008). Just Google It! Students constructing knowledge through internet travel. Paper presented at the Australian Association for Research in Education Conference, Brisbane, November 30 - December 4. Retrieved October 2, 2009 from, http://ocs.sfu.ca/aare/index.php/AARE_2008/AARE/paper/viewFile/263/123

Tapscott, D. 1(998). Growing up digital: the rise of the Net generation. New York: McGraw Hill.

Thrupp, R. (2008). Social groups and information communication technologies. Unpublished doctoral dissertation. Central Queensland University.

Toledo, C. (2007). Digital culture: immigrants and tourists responding to the natives' drumbeat, International Journal of Teaching and Learning in Higher Education, 19(1), 84-92.

Wellman, B. (2002). Little boxes, glocalization, and networked individualism? In M. Tanabe, P. van den Besselaar \& T. Ishida (Eds.), Digital Cities II: Computational and Sociological Approaches (pp. 10-25). Berlin: Springer. 